\title{
COVID-19 and ENT surgery: a brief review of essential precautions and triage
}

\author{
Akriti Sharma $^{1} \cdot$ Rohit Bhardwaj ${ }^{2}$ (I) \\ Received: 29 April 2020 / Accepted: 8 July 2020 / Published online: 11 July 2020 \\ c) Springer-Verlag GmbH Germany, part of Springer Nature 2020
}

\begin{abstract}
Purpose This study is a brief review of the existing knowledge on the ENT surgeon's approach towards management of patients during the COVID-19 pandemic. While it is being recommended to carry out only the emergent procedures and to postpone the non-urgent ones to a later date, this article is meant to provide an insight into triage of the ENT procedures and the various precautions to be taken into account by the ENT surgeons while carrying out a procedure during the COVID-19 pandemic.

Methods The ENT Cochrane, Pubmed and Web of Science databases were searched without a time limit using the terms 'COVID-19 and SARS-CoV-2 in conjunction with ENT surgery.

Results Elective and non urgent cases are best avoided during this time. Only absolutely essential and emergent procedures need to be carried out with the use of Personal protective equipment comprising of safety gown, N95 mask, safety goggles, disposable gloves and caps. There is a possibility of transmission of the SARS- CoV-2 through asymptomatic patients and hence all patients, even with an unknown COVID-19 status, need to undergo a preoperative screening. As all procedures under general anesthesia are aerosol generating, the use of Personal protective equipment (PPE) is recommended for all the health care workers present in the operation theater.

Conclusion A proper knowledge of triage would be of immense help to the ENT surgeon in minimizing the exposure to health care workers and patients during this pandemic. All patients with an unknown COVID-19 status should be considered suspects and essential precautions for their management be taken accordingly.
\end{abstract}

Keywords COVID-19 $\cdot$ ENT surgeon $\cdot$ Triage $\cdot$ Precautions

\section{Introduction}

The COVID-19 outbreak caused by the severe acute respiratory system corona virus- 2 was officially announced as a pandemic by the World Health Organization in March 2020. Amongst all healthcare specialists, otolaryngologists are at a high risk of being exposed to the Sars-cov2 virus [1,2]. The virus has been detected in swabs taken from the nose and throat of both symptomatic and asymptomatic patients [3].

Rohit Bhardwaj

drrohitbhardwaj90@gmail.com

1 Department of Otorhinolaryngology, SGT Medical College, Hospital and Research Institute, Village Budhera, Gurugram, Haryana 122505, India

2 Department of Otorhinolaryngology, Safdarjung Hospital and Vardhman Mahavir Medical College, Ansari Nagar, New Delhi 110029, India
The virus is known to survive on surfaces for up to $72 \mathrm{~h}$ and in the air for $3 \mathrm{~h}$ or more [4]. The characteristic contagious nature of this virus makes all aerosol generating procedures of the nose, oral cavity, pharynx, larynx, and trachea potentially hazardous [5]. When aerosolized, there is a propensity of this virus to spread and contaminate multiple surfaces including air exhaust vents that circulate air [6,7]. The otolaryngologists and head and neck surgeons, who assist and perform upper airway procedures, are at an increased risk of infection from aerosol and droplet contamination.

\section{Aim of the study}

Main aim of the study was to provide certain broad guidelines for triage of patients during the Covid-19 pandemic, along with highlighting the important practices meant to be followed for patients requiring ENT care during this pandemic. These guidelines and series of recommendations are 
drawn from our experience and recently published literature on COVID-19 from national and international bodies to support ENT surgeons as they respond to the outbreak.

\section{Methods}

The ENT Cochrane, Pubmed and Web of Science databases were searched without a time limit using the terms 'COVID19 and SARS-CoV-2 in conjunction with ENT surgery.The PubMed, ENT Cochrane and Web of Science databases were focusing on the newest report, using the terms "COVID19","ENT Surgery", "SARS-CoV-2" and "ENT Surgeon".

A total of 797 articles were originally identified using our search criteria. 763articles were excluded after reading the text because they were not relevant to the topic. Therefore, the total number of 34 studies were finally chosen to prepare this manuscript.

\section{Triage}

While the number of COVID-19 positive cases are rising exponentially worldwide, it is getting difficult every day to predict the time period for which the elective cases shall have to be postponed. Based on the most current compilation of information, the American Academy of Otolaryngology-Head and Neck Surgery has recommended that all otolaryngologists should limit providing patient care to those individuals with emergent medical conditions [8]. Though most authors recommend deferring elective day care surgeries [2], a few however believe that provisions for day care surgeries must be made, as the need for shifting the OT staff elsewhere might arise due to an overload on the health care system, in the future [9]. Keeping in mind the scarcity of health care providers and health facilities during the pandemic, we do not advocate day care elective surgeries in the current scenario. Day care procedures in otolaryngology could be aerosol generating and would increase the exposure to patients and doctors. We believe that, triage would be the key step by the otolaryngologist during the COVID-19 pandemic.

Triage would not only reduce the burden on the health care system, but also ensure minimal exposure of an individual to a hospital environment in addition to ensuring that all emergency cases are promptly and effectively dealt with by the health care workers. It would also ensure minimal exposure to the health care staff during this time without compromising essential patient care. In cases where it is ascertained that surgical intervention would be a part of the management, prioritization would be the next step.There is a detailed description of the levels of surgical priority, given by Royal College of physicians and surgeons Glasgow [10].

Our recommendation for triage is to categorize patients into two broad categories (Table 1).

In our opinion, if triage recommendations are implemented properly, the risk of exposure to both doctors and patients would decrease substantially.

\section{General considerations for ENT surgeons}

\section{Spread through asymptomatic patients}

An important observation to take note of by the otolaryngologist is that the disease could spread through asymptomatic patients. SARS-CoV-2 is found in high concentrations in the

Table 1 Triage of patients during COVID 19

Category I (emergency cases)

\begin{tabular}{|c|c|}
\hline Procedures & Management \\
\hline $\begin{array}{l}\text { Require immediate intervention and include cases like: } \\
\text { Foreign bodies of the airway } \\
\text { Foreign bodies of the esophagus, } \\
\text { Uncontrolled epistasis, } \\
\text { Airway obstructions and } \\
\text { Malignancies etc }\end{array}$ & $\begin{array}{l}\text { Prompt preparation of the patient for OT and educating the OT staff about essential } \\
\text { precautions to be taken in the OT } \\
\text { Only trained personnel to be allowed in the OT and donning and doffing procedures be } \\
\text { practiced before hand }\end{array}$ \\
\hline \multicolumn{2}{|l|}{ Category II (non-urgent cases) } \\
\hline Procedures & Management \\
\hline $\begin{array}{l}\text { Include all elective procedures such as: } \\
\text { Endoscopic sinus surgeries, } \\
\text { Tympanoplasties, } \\
\text { Mastoid surgeries, } \\
\text { Planned surgeries for benign diseases } \\
\text { Phonosurgeries, etc }\end{array}$ & $\begin{array}{l}\text { Deferring the procedure to a later date unless the otolaryngologist is suspicious of } \\
\text { impending complications } \\
\text { Patient counselling and reassurance } \\
\text { Conservative management/ extended maximal medical management of the cases would } \\
\text { be done } \\
\text { This would play a key role in the present situation as patients would be able to under- } \\
\text { stand the benefits of postponing their treatment to a later date }\end{array}$ \\
\hline
\end{tabular}


nose and throat in symptomatic and asymptomatic patients [3].The use of face masks has not been able to control the spread of COVID-19 in asymptomatic patients [1]. There are reports of asymptomatic, healthy patients, demonstrating visible ground-glass changes on radiography $[1,11]$. There are reports which prove that the virus can spread through non respiratory surfaces like eyes and hence the use of face masks may not be protective $[1,12]$. We recommend that, every patient being dealt with by an otolaryngologist should be treated like a COVID-19 suspect in the current scenario. The use of gloves and face masks should be made compulsory along with maintenance of adequate social distancing amongst patients in the OPD and essential precautions must be explained

\section{General precautions for ENT surgeons}

Head and neck examination that will include the mucous membranes should be performed maintaining the suggested level of precaution. All necessary precautions have been detailed in recent studies [24]. In the present situation, all ENT surgeries performed irrespective of whether the COVID-19 status is known or not, should be done using enhanced personal protective equipment, including an N95 respirator and goggles or Powered air-purifying respirator, disposable cap and gown, and disposable gloves. Powered instrumentation should be avoided during this time, and if carried out, the use of PAPR is recommended [13].

As all airway procedures including routine intubation and extubation are aerosol generating ones, sources recommend the pre-operative screening of all patients for COVID-19, $48 \mathrm{~h}$ prior to undergoing any surgery under general anesthesia [6, 14-16]. In accordance with the statement issued by the American Academy of Otolaryngology-Head and Neck Surgery in response to the CMS guidelines, we believe that "unless emergent, any surgery should only be undertaken after ascertaining the COVID-19 status and then performed using either N95 respirator masks with eye protection or PAPR [17]. The recommendation of CDC and WHO to wear protective gowns, gloves, goggles and medical masks to safeguard oneself from being infected with droplets, sounds noteworthy until supply chains for N95 masks are restored $[18,19]$.

\section{Use of powered air-purifying respirators vs N95 masks}

While a debate still exists in literature, regarding the use of N95 masks and tight-fitting goggles or the use of powered air-purifying respirators (PAPRs) [20, 21], we believe that the decision to use any one of them should differ from case to case and should be the call of the surgeon. Sources claim that the assigned protection factor range is 25-1000 for PAPRs and 10 for N95 masks [22]. However, the PAPRs have their own disadvantages of being cumbersome to use, limiting visibility due to fogging up, making the use of a headlight difficult and making the process of donning and doffing a potential source of infection [23]. On the other hand, ill-fitting N95 masks also have their own limitations of increasing the risk of exposure [23]. While both have their own advantages and shortcomings, decisions about which protection to use may depend on the settings, risks, and logistics [24].

Our view in this regard is that N95 masks are good enough to be used during all OPD examination procedures. The use of PAPR respirators should only be restricted to procedures which have high potential to generate aerosols. However we would prefer the use of PAPRs over N95 masks with goggles in a patient whose status is known to be COVID positive.

\section{Recommendations for specific procedure}

General precautions for otolaryngologists while carrying out procedures are described in detail in novel studies [23].

\section{Otological surgeries}

1. Most otology procedures should be postponed to a later date.

2. The process of drilling in the mastoid bone generates aerosols in large quantities [25]. While it is a known fact that COVID-19 virus spreads through the respiratory route, sources claim that the possibility of blood-borne transmission cannot be ruled out, although this risk is likely to be low $[26,27]$. There are studies that document the presence of corona viruses in the epithelium of the middle ear during upper respiratory tract infections, although there is no specific evidence to prove that there is presence of SARS CoV-2 in particular till date $[28,29]$. Hence ear surgery in the present scenario could put the operating surgeon and other OT staff at risk of acquiring infection by generating aerosols during the procedure.

3. Urgent indications such as acute mastoiditis, facial nerve injury, certain malignancies and other impending complications requiring immediate surgical intervention should be dealt with keeping all precautions in mind.

In our opinion, if an otological procedure is to be undertaken, the number of people being exposed to the risk, while the procedure is being carried out should be minimized. Also, all patients must be considered COVID-19 suspects if pre-operative screening is not available and the necessary precautions should be taken accordingly. 


\section{Tracheostomy}

Performing a tracheostomy on patients with suspected or confirmed COVID-19 will be challenging both for the ENT surgeons and the other health care professionals who are part of the team [30]. Avoiding early tracheostomy in patients with COVID-19 is suggested because of the higher viral load that may be present at this time [23]. In addition, early tracheostomy was not found to be associated with improved mortality or reduced length of intensive care unit stay in a randomized clinical trial of patients on mechanical ventilation [31].

Some sources recommend the formation of a specific 'COVID airway team' during this time for the purpose of carrying out tracheostomies and follow specific guidelines for the procedure during this pandemic [32].

\section{Sinonasal and upper airway procedures}

In our opinion, procedures like diagnostic nasal endoscopies and laryngoscopies should be avoided during this time. They must only be carried out in cases of suspected malignancy or foreign body removal. For upper airway procedures like intubation and extubation, the operation theatre staff must be cut down and appropriate PPE should be worn by all. We recommend special training of the OT staff during this time and advocate practicing donning and doffing of PPE by the health workers. Jet ventilation procedures would be hazardous and must be performed only under rare and necessary circumstances and with appropriate PPE, preferably in a negative-pressure room [23].

\section{Management of facial trauma}

During the COVID-19 pandemic, the main aim should be to minimize the exposure to the health workers, preserving PPE and above all be prompt in our decision making. Literature from sources claims that most facial injuries can be evaluated by the emergency medical provider and photos of imaging (if indicated) maybe documented in the patient's electronic medical record. If possible once the initial workup has been completed, most patients can be triaged without coming in direct contact by a member of the trauma team, unless absolutely essential [33]. After following the trauma triage protocol, if assessment and treatment of facial trauma is needed, our recommendation is to treat patients of unknown COVID-19 status as COVID-19 positive [23].

\section{Conclusion}

Based on our experience and a thorough reading of literature on the various recommendations being followed for surgeons worldwide, we can state with conviction that any surgical procedure which is non-urgent must be postponed to a later date, making triage of procedures the first and most important step towards ideal surgical management of a COVID-19 patient. We recommend pre-operative testing of all the patients with unknown COVID-19 status. In accordance with Stanford guidelines, we also support the concept that any patient could be infected with COVID-19 unless proven otherwise [34]. Hence, a comprehensive evaluation including relevant clinical history, correlating with results of the Rapid Antigen and RT-PCR tests and with findings of Chest CT scan, is advocated to ascertain the COVID-19 status of a patient.

Following the decision to carry out a procedure, a detailed knowledge of the precautions to be followed for the concerned procedure is a must. It is imperative to follow these measures to ensure the safety of both, the patients and the ENT surgeons while dealing with this pandemic. Keeping the above recommendations in mind, we are likely to emerge strong and successful in our management of ENT diseases during the COVID-19 pandemic.

Author contributions AS substantial contribution to the design of the manuscript, literature search, data analysis and interpretation. Preparing the main paper. RB literature search, proof reading and revising the manuscript. All authors read and approved the final manuscript. All listed authors have approved the manuscript before submission, including the names and order of authors.

Funding None.

\section{Compliance with ethical standards}

Conflict of interest The authors declare that they have no conflicts of interests.

Ethical approval Approval from the ethical committee was not required for this study. I confirm that the manuscript has not been published or submitted for publication to any other journal.

\section{References}

1. Chang D, Xu H, Rebaza A, Sharma L, Dela CC (2020) Protecting health-care workers from subclinical coronavirus infection. Lancet Respir Med 8(3):e13. https://doi.org/10.1016/s2213 -2600(20)30066-7

2. Why Surgeons Don't Want to Operate Right Now-BNN Bloomberg. BNN. https://www.bnnbloomberg.ca/why-surgeons-don-twant-to-operate-right-now-1.1411294. Published 2020. Accessed 22 Apr 2020

3. Zou L, Ruan F, Huang M et al (2020) SARS-CoV-2 viral load in upper respiratory specimens of infected patients. N Engl J Med 382(12):1177-1179. https://doi.org/10.1056/nejmc2001737

4. Van Doremalen N, Bushmaker T, Morris D et al (2020) Aerosol and surface stability of SARS-CoV-2 as compared with SARS-CoV-1. N Engl J Med 382(16):1564-1567. https://doi. org/10.1056/nejmc2004973 
5. Lu D, Wang H, Yu R, Yang H, Zhao Y (2020) Integrated infection control strategy to minimize nosocomial infection of coronavirus disease 2019 among ENT healthcare workers. J Hosp Infect 104(4):454-455. https://doi.org/10.1016/j.jhin.2020.02.018

6. Vukkadala N, Qian Z, Holsinger F, Patel Z, Rosenthal E (2020) COVID-19 and the otolaryngologist—preliminary evidence-based review. Laryngoscope. https://doi.org/10.1002/lary.28672

7. Ong S, Tan Y, Chia P et al (2020) Air, surface environmental, and personal protective equipment contamination by severe acute respiratory syndrome coronavirus 2 (SARS-CoV-2) from a symptomatic patient. JAMA. https://doi.org/10.1001/jama.2020.3227

8. COVID-19 Guidelines for Triage of Otolaryngology Patients. American College of Surgeons. https://www.facs.org/covid-19/ clinical-guidance/elective-case/otolaryngology. Published 2020. Accessed 22 Apr 2020

9. Guidance for ENT during the COVID-19 pandemic. Entuk.org. https://www.entuk.org/guidance-ent-during-covid-19-pandemic. Published 2020. Accessed 22 Apr 2020

10. England.nhs.uk. https://www.england.nhs.uk/coronavirus/wpcontent/uploads/sites/52/2020/03/C0221-specialty-guide-surgi cal-prioritisation-v1.pdf. Published 2020. Accessed 22 Apr 2020

11. Chan J, Yuan S, Kok K et al (2020) A familial cluster of pneumonia associated with the 2019 novel coronavirus indicating person-to-person transmission: a study of a family cluster. The Lancet 395(10223):514-523. https://doi.org/10.1016/s0140 $-6736(20) 30154-9$

12. Chinese expert thinks he contracted coronavirus through his eyeballs. South China Morning Post. https://www.scmp.com/news/ china/article/3047394/chinese-expert-who-came-down-wuhan -coronavirus-after-saying-it-was. Published 2020. Accessed 22 Apr 2020

13. Saadi R, Bann D, Patel V, Goldenberg D, May J, Isildak H (2020) A commentary on safety precautions for otologic surgery during the COVID-19 pandemic. Otolaryngol Head Neck Surg. https:// doi.org/10.1177/0194599820919741

14. Tnpatientsafety.com. https://www.tnpatientsafety.com/pubfiles/ covid-19/aerosolgeneratingprocedures.pdf. Published 2020. Accessed 22 Apr 2020

15. Latest News. Asohns.org.au. https://asohns.org.au/about-us/newsand-announcements/latest-news? article $=78$. Published 2020. Accessed 22 Apr 2020

16. Otolaryngologists May Contract COVID-19 During SurgeryENTtoday. ENTtoday. https://www.enttoday.org/article/otola ryngologists-may-contract-covid-19-during-surgery/. Published 2020. Accessed 22 Apr 2020

17. Coronavirus Disease 2019: Resources. American Academy of Otolaryngology-Head and Neck Surgery. https://www.entnet.org/ content/coronavirus-disease-2019-resources. Published 2020. Accessed 22 Apr 2020

18. COVID-19: Rational Use of Personal Protective Equipment (PPE). Nursingcenter.com. https://www.nursingcenter.com/ncblog/march -2020/covid-19-rational-use-of-personal-protective-equip. Published 2020. Accessed April 22, 2020.

19. https://newbp.bmj.com/topics/en-us/3000168/guidelines. Published 2020. Accessed 22 Apr 2020

20. Tay J, Khoo M, Loh W (2020) Surgical considerations for tracheostomy during the COVID-19 pandemic. JAMA Otolaryngol Head Neck Surg. https://doi.org/10.1001/jamaoto.2020.0764
21. Cleanspacetechnology.com.https://cleanspacetechnology.com/ wpcontent/uploads/2019/11/MDF2019_CleanSpace-To-papror-not-to-papr-V-roberts.-Can-J-respir-ther-2014.pdf. Published 2020. Accessed 22 Apr 2020

22. Board on Health Sciences Policy; Institute of Medicine (2015) The use and effectiveness of powered air purifying respirators in health care: workshop summary. National Academies Press, Washington, DC. https://doi.org/10.17226/18990

23. Givi B, Schiff B, Chinn S et al (2020) Safety recommendations for evaluation and surgery of the head and neck during the COVID19 pandemic. JAMA Otolaryngol Head Neck Surg. https://doi. org/10.1001/jamaoto.2020.0780

24. Wax R, Christian M (2020) Practical recommendations for critical care and anesthesiology teams caring for novel Coronavirus (2019-nCoV) patients. Can J Anesthesia 67(5):568-576. https:// doi.org/10.1007/s12630-020-01591-x

25. Jewett et al (1992) Blood-containing aerosols generated by surgical technique: a possible infectious hazard. Am IndHygAssoc J 53:228-231

26. Zhang W, Du R, Li B et al (2020) Molecular and serological investigation of 2019-nCoV infected patients: implication of multiple shedding routes. Emerg Microbes Infect 9(1):386-389. https://doi. org/10.1080/22221751.2020.1729071

27. Chang L, Yan Y, Wang L (2020) Coronavirus disease 2019: coronaviruses and blood safety. Transfus Med Rev. https://doi. org/10.1016/j.tmrv.2020.02.003

28. Heikkinen T, Thint M, Chonmaitree T (1999) Prevalence of various respiratory viruses in the middle ear during acute otitis media. N Engl J Med 340(4):260-264. https://doi.org/10.1056/nejm1 99901283400402

29. Wiertsema S, Chidlow G, Kirkham L et al (2011) High detection rates of nucleic acids of a wide range of respiratory viruses in the nasopharynx and the middle ear of children with a history of recurrent acute otitis media. J Med Virol 83(11):2008-2017. https ://doi.org/10.1002/jmv.22221

30. Murthy S, Gomersall C, Fowler R (2020) Care for critically Ill patients with COVID-19. JAMA 323(15):1499. https://doi. org/10.1001/jama.2020.3633

31. Young D, Harrison D, Cuthbertson B, Rowan K, TracMan Collaborators (2013) Effect of early vs late tracheostomy placement on survival in patients receiving mechanical ventilation. JAMA 309(20):2121

32. Entuk.org.https://www.entuk.org/sites/default/files/files/COVID $\% 2520$ tracheostomy\%2520guidance_compressed.pdf. Published 2020. Accessed 25 Apr 2020

33. Facial Plastic Surgery \& Aesthetic Medicine I Ahead of Print. Mary Ann Liebert, Inc., publishers. https://liebertpub.com/toc/ fpsam/0/0. Published 2020. Accessed 25 Apr 2020

34. New algorithm aims to protect surgical team members against infection with COVID-19 virus. ScienceDaily. https://www.scien cedaily.com/releases/2020/04/200406112526.htm. Published 2020. Accessed 25 Apr 2020

Publisher's Note Springer Nature remains neutral with regard to jurisdictional claims in published maps and institutional affiliations. 